\title{
Nucleolin Mediates LPS-induced Expression of Inflammatory Mediators and Activation of Signaling Pathways*
}

\author{
Li FANG ${ }^{1 \#}$, Kang-kai WANG ${ }^{2}$, Qing HUANG ${ }^{1}$, Feng CHENG $^{1}$, Fang HUANG ${ }^{1}$, Wei-wei LIU ${ }^{1}$ \\ ${ }^{1}$ Department of Cardiology, the First Hospital of Changsha, Changsha 410008, China \\ ${ }^{2}$ Department of Pathophysiology, Xiangya School of Medicine, Central South University, Changsha 410008, China
}

(C) The Author(s) 2020

\begin{abstract}
Summary: In this study, we investigated the effects of nucleolin on lipopolysaccharide (LPS)induced activation of MAPK and NF-KappaB (NF- $\kappa \mathrm{B})$ signaling pathways and secretion of TNF- $\alpha$, IL-1 $\beta$ and HMGB1 in THP-1 monocytes. Immunofluorescence assay and Western blotting were used to identify the nucleolin expression in cell membrane, cytoplasm and nucleus of THP1 monocytes. Inactivation of nucleolin was induced by neutralizing antibody against nucleolin. THP-1 monocytes were pretreated with anti-nucleolin antibody for $1 \mathrm{~h}$ prior to LPS challenge. The irrelevant IgG group was used as control. Secretion of inflammatory mediators (TNF- $\alpha$, IL$1 \beta$ and $\mathrm{HMGB} 1$ ) and activation of MAPK and NF- $\mathrm{B} / \mathrm{I}-\kappa \mathrm{B}$ signaling pathways were examined to assess the effects of nucleolin on LPS-mediated inflammatory response. Nucleolin existed in cell membrane, cytoplasm and nucleus of THP-1 monocytes. Pretreatment of anti-nucleolin antibody significantly inhibited the LPS-induced secretion of TNF- $\alpha$, IL-1 $\beta$ and HMGB1. P38, JNK, ERK and NF- $\kappa B$ subunit $\mathrm{p} 65$ inhibitors could significantly inhibit the secretion of IL-1 $\beta$, TNF- $\alpha$ and HMGB1 induced by LPS. Moreover, the phosphorylation of p38, JNK, ERK and p65 (or nuclear translocation of p65) was significantly increased after LPS challenge. In contrast, pretreatment of anti-nucleolin antibody could significantly inhibit the LPS-induced phosphorylation of p38, JNK, ERK and p65 (or nuclear translocation of p65). However, the irrelevant IgG, as a negative control, had no effect on LPS-induced secretion of TNF- $\alpha$ and IL-1 $\beta$ and phosphorylation of $\mathrm{p} 38$, JNK, ERK and p65 (or nuclear translocation of p65). We demonstrated that nucleolin mediated the LPS-induced activation of MAPK and NF- $\kappa B$ signaling pathways, and regulated the secretion of inflammatory mediators (TNF- $\alpha$, IL- $1 \beta$ and HMGB1).
\end{abstract}

Key words: nucleolin; THP-1 monocytes; lipopolysaccharide; MAPK; NF-кB signaling pathway; inflammatory mediators

As a type of phosphoric acid protein in eukaryotic cells, nucleolin (rRNA) is mainly involved in the ribosomal transcription, ribosome subunit assembly, maturation and so on ${ }^{[1-4]}$. In most cells, nucleolin is mainly expressed in the nucleus, but it can also exist in the cytoplasm in glycosylated or phosphorylated form. Recent studies have found that nucleolin is expressed on the surface of a variety of immune cells, tumor cells and vascular endothelial cells, it acts as receptors for many proteins, viruses and bacteria or co-receptors, and it is involved in the pathogenic microbial infection, inflammation, angiogenesis and other biological processe $^{[5-8]}$. Other studies have confirmed that nucleolin expressed on the cell membrane of THP-1 monocytic

"Corresponding author, Li FANG, E-mail: 527384528@, qq.com

${ }^{*}$ This work was supported by grants from Bureau of Science and Technology of Changsha, China (No. Kq1701007) and Hunan Natural Science Foundation, China (No. 2018JJ6127). cells can recognize polysaccharide in CD43 of early apoptotic cells and mediate phagocytosis of early apoptotic Jurkat cells ${ }^{[9]}$.

Lipopolysaccharide (LPS), also known as an endotoxin, plays a dominant role in Gram-negative bacteria-induced systemic inflammatory response syndrome (SIRS). After binding to LPS binding protein (LBP) in serum, LPS/LBP complex interacts with several membrane receptors, such as CD14, toll-like receptor 2, 4 (TLR2, 4), triggering receptor expressed on myeloid cells (TREM-1) and macrophage scavenger receptor (MSR) on monocytes/macrophages and polymorphonuclear leukocytes. Such interactions subsequently activate MAPK and/or NF-KappaB (NF$\kappa \mathrm{B})$ signaling pathways as well as their corresponding transcription factors, triggering the up-regulation of inflammatory mediators, such as tumor necrosis factor alpha (TNF- $\alpha$ ), interleukin-1 $\beta$ (IL-1 $\beta$ ), high mobility group box 1 (HMGB1) and so on ${ }^{[10-12]}$. However, it remains unclear whether nucleolin can affect the 
expression of LPS-induced inflammatory mediators and the activation of intracellular signaling pathways. Based on the general structures (polysaccharide fraction) of CD43 molecule and LPS, we inferred that nucleolin on the cell surface might recognize LPS. All of these findings indicated that nucleolin might be involved in mediating the expression of the inflammatory mediators induced by LPS and the activation of intracellular signaling pathways.

The present study aimed to investigate the roles of nucleolin in LPS-induced activation of MAPK and NF$\kappa \mathrm{B}$ signaling pathways and secretion of inflammatory mediators (TNF- $\alpha$, IL-1 $\beta$ and HMGB1) in THP-1 monocytes. Human THP-1 cells were pretreated with anti-nucleolin antibody for $1 \mathrm{~h}$ prior to LPS challenge. Moreover, we also examined the secretion of inflammatory mediators (TNF- $\alpha$, IL- $1 \beta$ and HMGB1) and activation of MAPK (p38, JNK and ERK) and $\mathrm{NF}-\mathrm{\kappa B}$ signaling (NF- $\mathrm{B}$ subunit p65) pathways in order to assess the role of nucleolin in LPS-mediated inflammatory response.

\section{MATERIALS AND METHODS}

All experiments were performed under conditions specified by law and reviewed and approved by the ethics committee of the First Hospital of Changsha and carried out in accordance with the approved protocol.

\subsection{Culture of THP-1 Cells and Experimental Groups}

THP- 1 cells at a density of $2 \times 10^{6}$ per bottle (T75) were maintained in RPMI-1640 medium supplemented with $10 \%$ fetal bovine serum, $2 \mathrm{mmol} / \mathrm{L}$ L-glutamine, $100 \mathrm{U} / \mathrm{mL}$ ampicillin and $100 \mu \mathrm{g} / \mathrm{mL}$ streptomycin at $37^{\circ} \mathrm{C}$ in an incubator containing $5 \% \mathrm{CO}_{2}$.

Cells were divided into three groups as follows: (1) LPS group, in which THP-1 cells were stimulated with LPS (1 mg/L) for various durations (no serum). The secretion of inflammatory mediators was determined at $0,4,12,24$ and $48 \mathrm{~h}$, while the phosphorylation of p38, JNK, ERK and NF- $\mathrm{kB}$ subunit p65 was detected at 0,30 and $60 \mathrm{~min}$; (2) LPS $+\mathrm{C} 23$ Abs group, in which THP-1 cells were pretreated with $1 \mathrm{mg} / \mathrm{L}$ C23 $\mathrm{Abs}^{[13,14]}$ (mouse anti-C23 monoclonal antibody was purchased from Santa Cruz1, USA) for $1 \mathrm{~h}$ and then stimulated with $1 \mathrm{mg} / \mathrm{L}$ LPS for different durations (no serum); (3) $\mathrm{LPS}+\operatorname{IgG}$ group (negative control group), in which THP-1 cells were pretreated with $1 \mathrm{mg} / \mathrm{L}$ IgG for 1 $\mathrm{h}$ and then stimulated with $1 \mathrm{mg} / \mathrm{L}$ LPS for different durations (no serum).

\subsection{Immunocytochemistry}

Cells were cultured on glass coverslips, fixed with $4 \%$ formaldehyde and permeabilized with $0.1 \%$ Triton $\mathrm{X}-100$ at $4^{\circ} \mathrm{C}$ for $10 \mathrm{~min}$. Coverslips were blocked with $2 \% \mathrm{BSA}$ at room temperature for $1 \mathrm{~h}$ and incubated with mouse anti-C23, Fas (Santa Cruz Biotechnology, USA) or rabbit anti-NF- $\mathrm{kB}$ subunit p65 mAbs (Santa
Cruz Biotechnology, USA), followed by incubation with $\mathrm{Cy} 3$ or FITC-conjugated sheep anti-mouse $\mathrm{IgG}$ or FITC-conjugated sheep anti-rabbit IgG (BosterBiotech, USA), respectively. Nuclear morphology was analyzed with Hoechst 33258 staining. Cells were washed with PBS containing $0.2 \%$ BSA three times $(3 \mathrm{~min}$ each wash) between all incubation steps. Images were acquired with a fluorescence microscope (ECLIPSE 80i, Nikon, Japan).

\subsection{Extraction of Cell Membrane and Nuclear Protein Fractions}

Extraction of cell membrane and nuclear proteins was conducted according to the Pierce eukaryotic cell membrane and nuclear protein extraction kits (Pierce, USA), respectively. The components of cell membrane, cytoplasm and nuclear proteins were collected and stored at $-70^{\circ} \mathrm{C}$.

\subsection{Western Blotting Analysis}

Protein concentrations were determined by Bradford assay. Albumin was used to establish the standard curve. Equal amounts of whole-cell lysates were subjected to $10 \%$ sodium dodecyl sulphatepolyacrylamide gel electrophoresis (SDS-PAGE) and then transferred onto PVDF membranes. Blots were incubated with primary Abs specific for phospho-p38 (T180/Y182, R\&D Cell Signaling Technology, USA), phospho-ERK1/2 (Thr202/Tyr204, Cell Signaling Technology, USA), phospho-JNK1/2 (Thr183/Tyr185, Cell Signaling Technology, USA), NF-kB subunit p65 (Santa Cruz Biotechnology, USA), GAPDH (Jingmei Biotechnology, China) or proliferating cell nuclear antigen (PCNA, BD Biosciences, USA) at $25^{\circ} \mathrm{C}$ for $2 \mathrm{~h}$. Subsequently, the bolts were incubated with peroxidase-conjugated secondary Abs (Boster Biotech) at $25^{\circ} \mathrm{C}$ for $1 \mathrm{~h}$. The immunoreactive signals were visualized with chemiluminescence (Beyotime Institute of Biotechnology, China) according to the manufacturer's instructions and quantitated by Scion image software.

\subsection{Enzyme Linked Immunosorbent Assay}

Levels of IL-1 $\beta$, TNF- $\alpha$ and HMGB1 in the culture medium were determined by commercially available ELISA kits for TNF- $\alpha$, IL-1 $\beta$ (Cat. No: EK0392, ab181421, Wuhan Boster Company, China) and HMGB1 (Cat. No: F1062, Shanghai Xitang Biotechnology Co., Ltd., China) according to the manufacturer's instructions. Cell culture supernatant was collected 4, 12, 24 and $48 \mathrm{~h}$ after LPS challenge, and $200 \mu \mathrm{L}$ supernatant was added into a 96-well plate coated with the corresponding mAbs of inflammatory factors and incubated at $37^{\circ} \mathrm{C}$ for $2 \mathrm{~h}$. Subsequently, liquid was removed, and $200 \mu \mathrm{L}$ enzyme-labeled secondary antibody was added into each well, followed by incubation at $37^{\circ} \mathrm{C}$ for $2 \mathrm{~h}$. Wells were washed with TBS $(0.01 \mathrm{mmol} / \mathrm{L})$ three times ( $3 \mathrm{~min}$ each wash) and then incubated with substrate solution $(200 \mu \mathrm{L})$ at 
$25^{\circ} \mathrm{C}$ for $30 \mathrm{~min}$. Next, the stop solution was added to terminate the reaction. The absorbance $(A)$ value was measured by an enzyme-labeled instrument (Startfax 2100, USA) at a wavelength of $450 \mathrm{~nm}$. The sample concentration was calculated by linear equation.

\subsection{Statistical analysis}

Data were expressed as means \pm SEM based on at least three independent experiments. Statistical analysis was performed by one-way ANOVA (LSD test) for multiple testing. The differences were considered as statistically significant if $P<0.05$.

\section{RESULTS}

\subsection{Nucleolin in Cell Membrane, Cytoplasm and Nucleus of THP-1 Monocytes}

Immunofluorescence analysis showed that nucleolin was localized on the cell surface of THP-1 monocytes. Similarly, Fas was localized on the surface of the cell membrane in the positive control group (fig. 1). Western blotting analysis showed that nucleolin existed in cell membrane, cytoplasm and nucleus, while Fas was only expressed in cell membrane, and GAPDH was used as the internal control of cytoplasmic protein, indicating no obvious contamination between the components (fig. 2). These findings suggested that nucleolin could be expressed on the cell membrane and in the cytoplasm or nucleus of THP-1 monocytes.

\subsection{Role of Nucleolin in LPS-induced Expression of Inflammatory Mediators in THP-1 Monocytes}

Under normal culture conditions, THP-1 cells secreted a small amount of TNF- $\alpha$, IL- $1 \beta$ and HMGB1. After THP-1 cells were stimulated with LPS for 0, 4, 8 and $12 \mathrm{~h}$, the LPS-induced secretion of TNF- $\alpha$ and IL-1 $\beta$ was increased in a time-dependent manner. Similarly, after THP-1 cells were stimulated with LPS for $0,12,24$ and $48 \mathrm{~h}$, the LPS-induced secretion of HMGB1 was increased in a time-dependent manner. Pretreatment of anti-nucleolin antibody significantly inhibited such LPS-induced secretion of TNF- $\alpha$, IL-1 $\beta$ and HMGB1. However, the irrelevant $\mathrm{IgG}$, which was

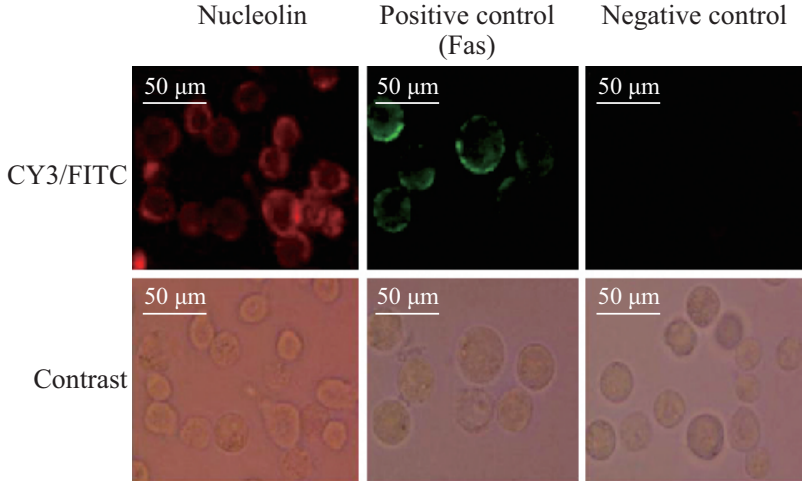

Fig. 1 Localization of nucleolin in THP-1 monocytes

Fas: transmembrane receptor that belongs to TNF family as positive control. Contrast: same visual field under contrast phase; CY3: expression of nucleolin with CY3labeled Abs (red); FITC: expression of fas with FITClabeled Abs (green)

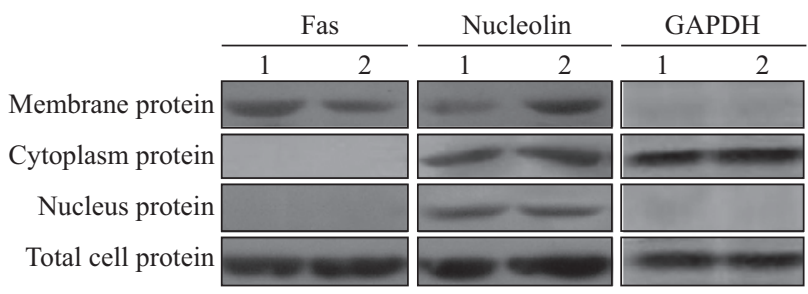

Fig. 2 Subcellular distributions of nucleolin using Western blotting analysis

samples 1 and 2: two samples of cells derived from the different culture flasks; membrane protein: membrane fractions of THP-1; cytoplasm protein: cytoplasmic fractions of THP-1; nucleus protein: nucleus fractions of THP-1; total cell protein: whole cell lysates of THP-1

used as a negative control, had no effect on LPS-induced secretion of TNF- $\alpha$, IL- $1 \beta$ and HMGB1 (fig. 3).

2.3 Role of MAPK and NF-кB Signaling Pathways in LPS-induced Inflammatory Mediator Secretion with Specific Inhibitors

We observed the causative role of MAPK and NF$\kappa \mathrm{B}$ signaling pathways in LPS-induced IL- $1 \beta$, TNF- $\alpha$ and HMGB1 secretion with specific inhibitors. After
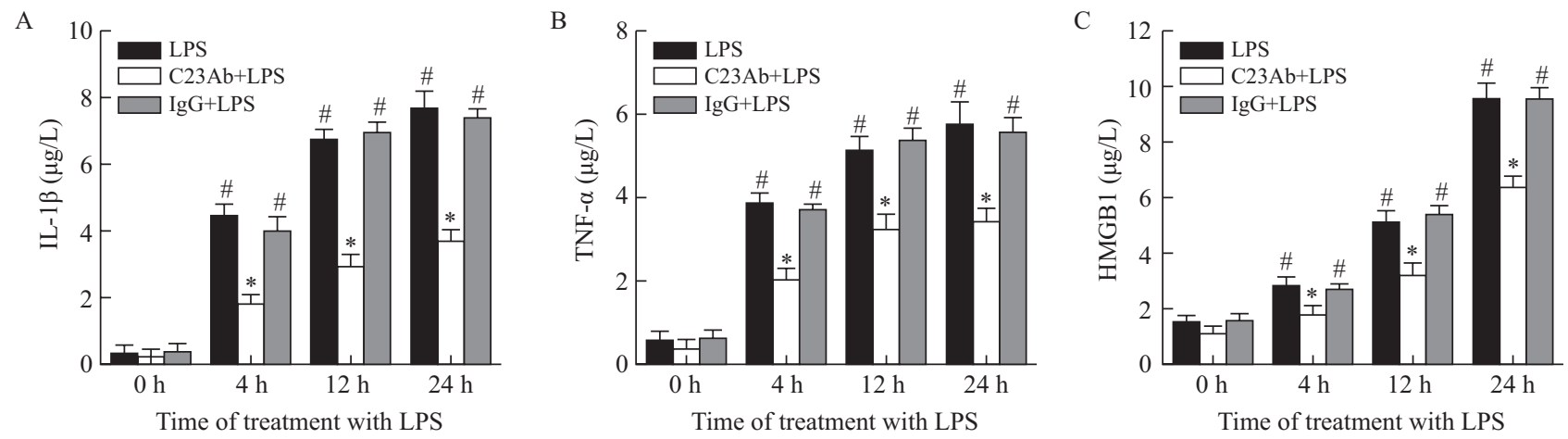

Fig. 3 ELISA showed the inhibition of the effect of pretreatment of anti-nucleolin antibody on the secretion of TNF- $\alpha$, IL-1 $\beta$ and HMGB1 in THP-1 monocytes

A: secretion of IL-1 $\beta$; B: secretion of TNF- $\alpha$; : secretion of HMGB1. Data were expressed as mean $\pm \mathrm{SD}, n=5 ;{ }^{*} P<0.05 v s$. the LPS group and IgG+LPS group, ${ }^{\#} P<0.05 v s$. the 0 h group 
THP-1 cells were stimulated with LPS for $48 \mathrm{~h}$, the LPS-induced secretion of IL- $1 \beta$, TNF- $\alpha$ and HMGB1 was significantly increased. However, p38, JNK, ERK and p65 inhibitors could significantly inhibit the secretion of IL-1 $\beta$, TNF- $\alpha$ and HMGB1 induced by LPS (fig. 4).

\subsection{Role of Nucleolin in LPS-induced Activation of Signaling Pathways in THP-1 Monocytes}

Results showed that the phosphorylation of $\mathrm{p} 38$, JNK and ERK was significantly increased at $30 \mathrm{~min}$ and 60 min after LPS challenge. Pretreatment of antinucleolin antibody could significantly inhibit the phosphorylation of p38, JNK and ERK. However, the irrelevant $\operatorname{IgG}$ had no effect on LPS-induced phosphorylation of $\mathrm{p} 38, \mathrm{JNK}$ and ERK. In addition to MAPK activation, the NF- $\kappa \mathrm{B}$ p 65 signal transduction pathways are also involved in signaling pathways of inflammatory response. The results showed that little p65 was distributed in the nucleus of THP-1 cells without LPS stimulation. After LPS challenge for 30 min, the distribution of p65 in the nucleus was increased. After LPS challenge for $60 \mathrm{~min}$, the distribution of p65 in the nucleus was significantly increased. Pretreatment of anti-nucleolin antibody had significantly inhibitory effect on LPS-induced phosphorylation of NF$\kappa \mathrm{B}$ p65 (fig. 5). Meanwhile, immunofluorescence analysis showed that nuclear translocation of $\mathrm{p} 65$, the transcriptionally active component of the NF- $\kappa \mathrm{B}$ complex, induced by LPS was strongly inhibited by pretreatment of anti-nucleolin antibody (fig. 6).

\section{DISCUSSION}

A large number of studies have shown that nucleolin is expressed on the cell surface of a variety of cells, and it participates in bacterial and viral invasions of host cells, inflammatory immune response, angiogenesis, inhibition of tumor cell proliferation, and other physiological processes ${ }^{[15-19]}$. However, many investigators have demonstrated that LPS-induced inflammatory response can't be completely abolished by functional deficiency of CD14, TLR2, 4 and LBP. Therefore, LPS/LBP-CD14-TLR2, 4 is not the only pathway during LPS-induced inflammation ${ }^{[20,21]}$. These results suggest that there must be other LPS receptors on the membrane of inflammatory cells. According to the current knowledge of cell-surface nucleolin, we postulated that cell-surface nucleolin might serve as a novel receptor of LPS, and it was involved in the LPS-mediated inflammation. In the present study, we found that nucleolin existed on the surface of THP-1 cell membrane by indirect immunofluorescence and immunoblotting. This finding laid a foundation for studying the role of nucleolin in the expression and secretion of inflammatory mediators and activation of signaling pathways in THP-1 cells.

At present, it is generally believed that TNF- $\alpha$ and IL-1 $\beta$, the "early" pro-inflammatory mediators, are the key inflammatory factors causing uncontrolled inflammatory response and tissue damage ${ }^{[22,23]}$. Recent studies have shown that HMGB1 is a key "late" proinflammatory mediator, which plays an important role in sepsis. Moreover, HMGB1 can further induce the expression and release of various proinflammatory mediators. In addition, it is also involved in the activation of MAPK signal transduction pathway and the nuclear translocation of NF- $\mathrm{B}$ (p65) signaling pathway ${ }^{[24,}$ ${ }^{25]}$. Our previous RT-PCR results have shown that the expression of TNF- $\alpha$ and IL- $1 \beta$ mRNA was significantly increased at 2 and $3 \mathrm{~h}$ after the treatment with 1000 $\mu \mathrm{g} / \mathrm{L}$ LPS, respectively. After $1 \mathrm{~h}$ of pretreatment with anti-nucleolin antibody, the expression levels of
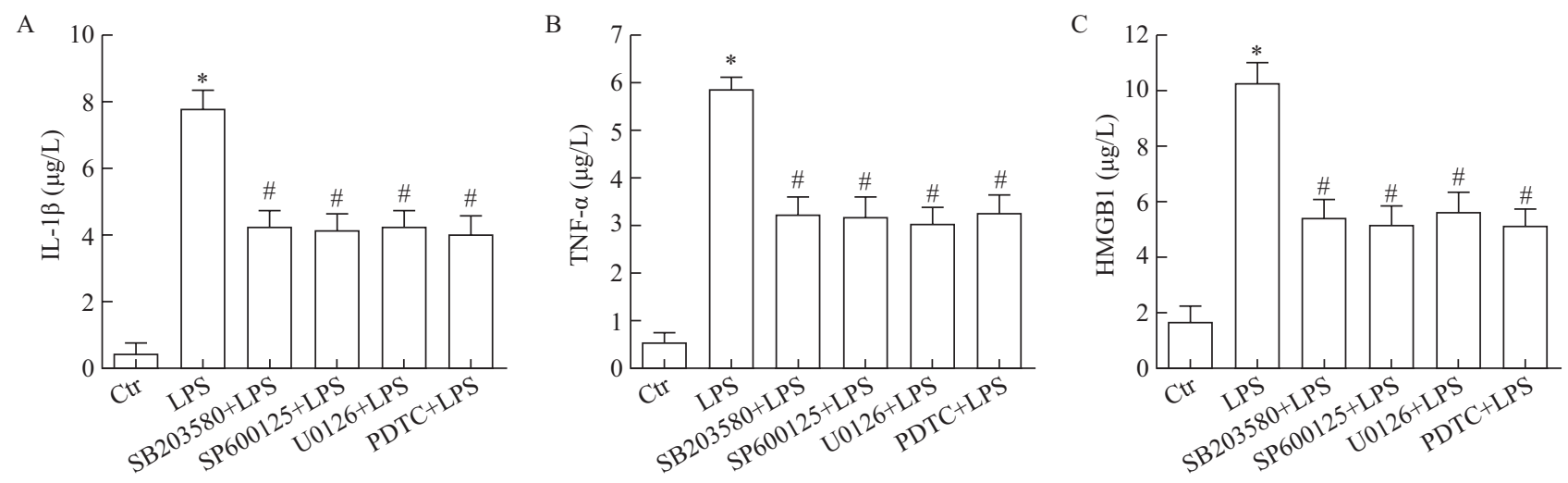

Fig. 4 ELISA showed the causative role of MAPK and NF- $\kappa$ B signaling pathways in LPS-induced IL-1 $\beta$, TNF- $\alpha$ and HMGB1 secretion with specific inhibitors (SB203580 preincubated with $20 \mu \mathrm{mol} / \mathrm{L}$ for $1 \mathrm{~h}$ and cultured for $24 \mathrm{~h}$ in the presence of $1 \mathrm{mg} / \mathrm{L}$ LPS; SP600125 preincubated with $40 \mathrm{nmol} / \mathrm{L}$ for $1 \mathrm{~h}$ and cultured for $24 \mathrm{~h}$ in the presence of $1 \mathrm{mg} / \mathrm{L} \mathrm{LPS}$; U0126 preincubated with $60 \mathrm{nmol} / \mathrm{L}$ for $1 \mathrm{~h}$ and cultured for $24 \mathrm{~h}$ in the presence of $1 \mathrm{mg} / \mathrm{L} \mathrm{LPS}$; PDTC preincubated with $100 \mu \mathrm{mol} / \mathrm{L}$ for $1 \mathrm{~h}$ and cultured for $48 \mathrm{~h}$ in the presence of $1 \mathrm{mg} / \mathrm{L} \mathrm{LPS}$ )

A: effects of p38, JNK, ERK and p65 inhibitors on LPS-induced IL-1 $\beta$ secretion; B: effects of p38, JNK, ERK and p65 inhibitors on LPS-induced TNF- $\alpha$ secretion; C: effects of p38, JNK, ERK and p65 inhibitors on LPS-induced HMGB1 secretion. Ctr: control group; SB203580: P38 inhibitor; SP600125: JNK inhibitor; U0126: ERK inhibitor; PDTC: p65 inhibitor. Data were expressed as mean $\pm \mathrm{SD}, n=5$. ${ }^{*} P<0.05 v s$. control group, ${ }^{\#} P<0.05 v s$. LPS group and control group. Ctr: control group 


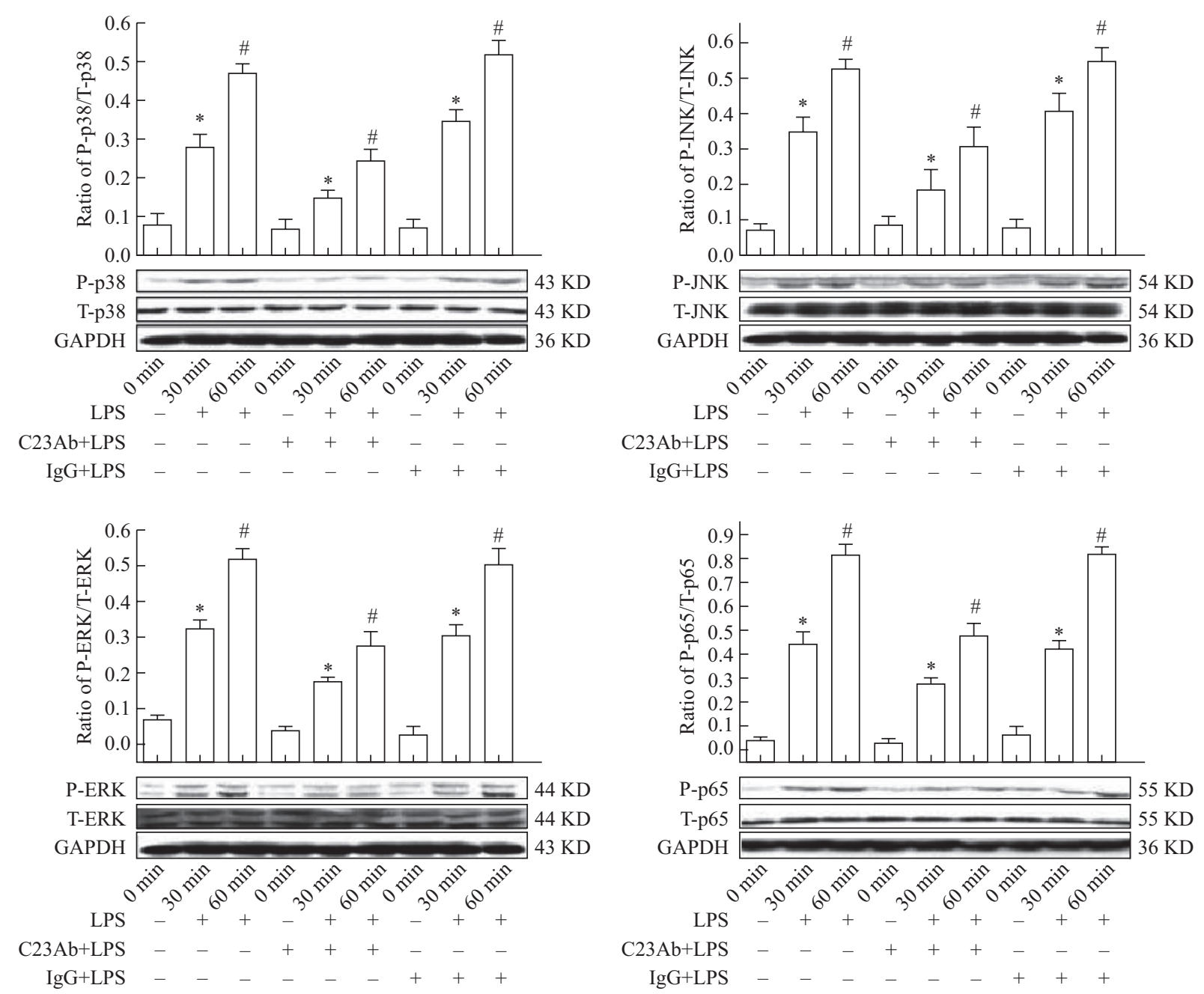

Fig. 5 Western blotting analysis showed the effect of pretreatment of anti-nucleolin antibody on the phosphorylation of p38, JNK, ERK and p65

Relative densitometric assay for the ratio of $\mathrm{p} 38$, JNK, ERK and $\mathrm{p} 65$ protein bands to T-p38, T-JNK, T-ERK and T-p65 protein bands respectively. Data were expressed as mean $\pm \mathrm{SD}, n=5$. ${ }^{*} P<0.05$ vs. LPS group, ${ }^{\sharp} P<0.05$ vs. C23Ab + LPS group and LPS group

A
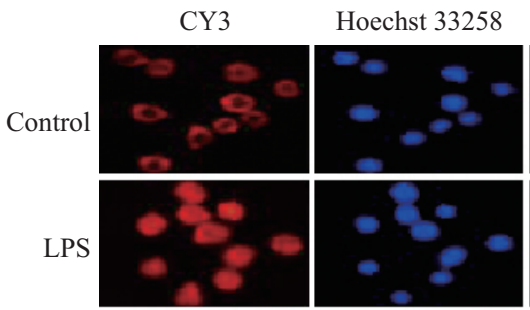

$\mathrm{C} 23 \mathrm{Ab}+\mathrm{LPS}$
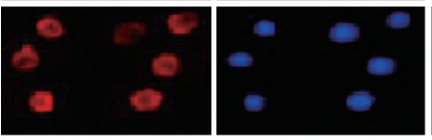

$\operatorname{IgG}+\mathrm{LPS}$

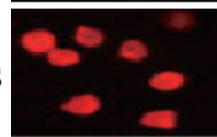

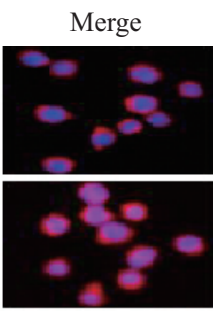

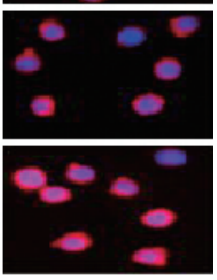

B

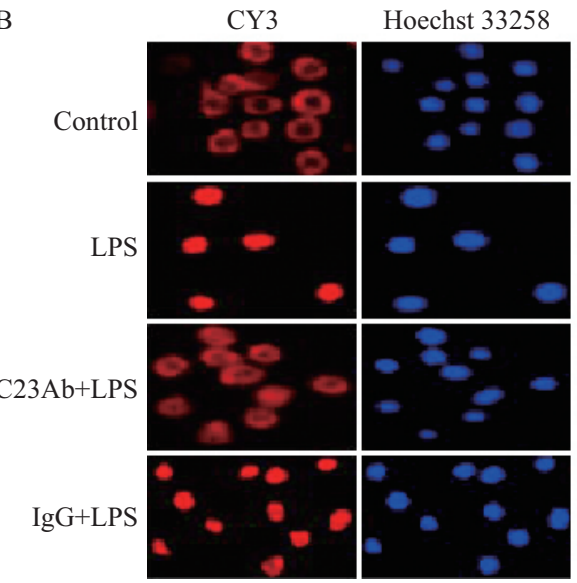

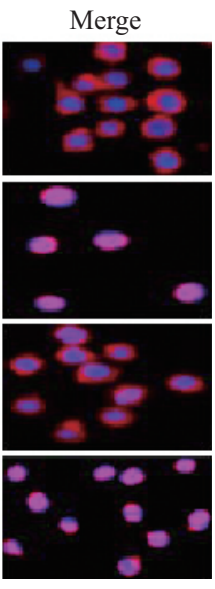

Fig. 6 Indirect immunofluorescence showed the effect of pretreatment of anti-nucleolin antibody on the nuclear translocation of NF- $\mathrm{B}$ (p65) induced by LPS

A: LPS for $30 \mathrm{~min}$. B: LPS for $60 \mathrm{~min}$

TNF- $\alpha$ and IL- $1 \beta$ mRNA were decreased as compared with the untreated group and irrelevant $\mathrm{IgG}+\mathrm{LPS}$ group $^{[26]}$. It preliminarily explained that cell-surface nucleolin was involved in the expression and secretion of inflammatory mediators (IL-1 $\beta$ and TNF- $\alpha$ ) of THP-1 cells induced by LPS. However, whether the 
cell surface nucleolin mediated the expression and secretion of advanced inflammatory mediators caused by LPS remained unclear. The signaling pathways through which nucleolin on the surface of THP-1 cells mediates the inflammatory response of LPS need to be further explored. In the present study, we attempted to clarify the roles of nucleolin in LPS-induced secretion of TNF- $\alpha$, IL-1 $\beta$ and HMGB1 in monocytes. THP1 monocytes were pretreated with anti-nucleolin antibody or IgG for $1 \mathrm{~h}$ prior to LPS challenge. Secretion of inflammatory mediators (TNF- $\alpha$, IL-1 $\beta$ and HMGB1) was examined to assess the cell-surface nucleolin in LPS-mediated inflammatory response. The unrelated antibody treatment (IgG group) was used as a control. ELISA results showed that the levels of TNF- $\alpha$ and IL- $1 \beta$ were significantly increased at 4 , 12 and $24 \mathrm{~h}$ after LPS challenge, and the HMGB1 level was also significantly increased at 12,24 and $48 \mathrm{~h}$ after LPS challenge. Pretreatment of anti-nucleolin antibody significantly inhibited the LPS-induced secretion of TNF- $\alpha$, IL- $1 \beta$ and HMGB1 as compared with the LPSstimulated cells. However, the irrelevant $\operatorname{IgG}$ had no effect on LPS-induced secretion of TNF- $\alpha$, IL- $1 \beta$ and HMGB1. These results suggested that nucleolin existed in cell membrane, cytoplasm and nucleus of THP-1 monocytes, and it was involved in the LPS-mediated expression and secretion of TNF- $\alpha$, IL- $1 \beta$ and HMGB1. The action mechanism might be that nucleolin existing on the cell surface of THP-1 monocytes functioned as LPS receptor, or the interaction of LPS with other LPS receptors resulted in the transformation of inflammatory signals into the cells. Previous studies have shown that cell-surface nucleolin can act as a receptor for a variety of protein molecules, bacteria and viruses, many ligands can be transported into the cell via binding to cell-surface nucleolin, and molecular chaperone plays a fundamental role in the intracellular translocation of extracellular ligands ${ }^{[13,27,28]}$. However, it remains largely unexplored whether nucleolin is involved in the regulation of LPS-induced inflammatory signals. We observed the causative role of MAPK and NF- $\kappa B$ signaling pathways in LPS-induced IL- $1 \beta$, TNF- $\alpha$ and HMGB1 secretion with specific inhibitors. The results confirmed that p38, JNK, ERK and p65 inhibitors could significantly inhibit the secretion of IL-1 $\beta$, TNF- $\alpha$ and HMGB1 induced by LPS. It suggested that LPS induced IL-1 $\beta$, TNF- $\alpha$ and HMGB1 secretion through MAPK and NF- $\mathrm{KB}$ signaling pathways. In order to further reveal the mechanism underlying the inflammatory response mediated by the nucleolin, THP1 cells were pretreated with anti-nucleolin antibody for $1 \mathrm{~h}$ prior to LPS challenge. Activation of MAPK and NF- $\mathrm{kB}$ signaling pathways was detected to assess the role of cell-surface nucleolin in LPS-mediated inflammatory response. Following pretreatment of anti-nucleolin antibody for $1 \mathrm{~h}$, THP-1 monocytes were challenged with LPS for $30 \mathrm{~min}$ and $60 \mathrm{~min}$, and the LPS-stimulated group and irrelevant IgG group were used as controls. Total cell protein and nuclear protein were extracted, and activation of JNK, ERK, p38 and p65 in the MAPK and NF- $\mathrm{KB}$ signaling pathways was detected by Western blotting analysis. Results showed that the phosphorylation of p38, JNK, ERK and p65 was significantly increased at $30 \mathrm{~min}$ and $60 \mathrm{~min}$ after LPS challenge. Pretreatment of anti-nucleolin antibody could significantly inhibit the phosphorylation of $\mathrm{p} 38$, JNK, ERK and p65 as compared with the LPS group. However, the irrelevant IgG had no effect on LPSinduced phosphorylation of p38, JNK, ERK and p65. Similar to this finding, pretreatment of anti-nucleolin antibody could significantly inhibit the nuclear translocation of NF- $\mathrm{kB}$ (p65). However, the irrelevant IgG had no effect on LPS-induced phosphorylation (the nuclear translocation) of p65, suggesting that nucleolin mediated LPS-induced activation of MAPK and NF$\kappa \mathrm{B}$ signaling pathways as well as the expressions of inflammatory mediators (TNF- $\alpha$, IL- $1 \beta$ and HMGB1).

A large number of studies have shown that cellsurface nucleolin can act as a receptor for a variety of protein molecules, bacteria and viruses, and it plays a role in the transmission of extracellular signals ${ }^{[7,9,29]}$. Hirano et al have found that nucleolin on cell membrane of THP-1 cells can recognize polysaccharide in CD43 of early apoptotic Jurkat cell membrane and mediate phagocytosis of early apoptotic Jurkat cells. Anti-CD43 antibody, anti-nucleolin antibody and pretreatment of oligosaccharide can inhibit the recognition and phagocytosis of THP-1 cells to the early apoptotic cells ${ }^{[9]}$. Based on above-mentioned data, we hypothesized that nucleolin on the cell membrane might be involved in the inflammatory response induced by LPS. In summary, in this study, our results demonstrated that pretreatment of anti-nucleolin antibody inhibited the LPS-induced expression and secretion of inflammatory mediators (TNF- $\alpha$, IL-1 $\beta$ and HMGB1) by inactivating MAPK and NF- $\kappa$ B pathways. However, we also found that the LPS-induced expression and secretion of inflammatory mediators (TNF- $\alpha$, IL-1 $\beta$ and HMGB1) and activation of MAPK and NF- $\kappa B$ signaling pathways could not be completely eliminated after blocking the effect of nucleolin. This finding suggested that other receptors were involved in the activation of the above-mentioned inflammatory mediators and inflammatory signaling pathways induced by LPS, such as scavenger receptors, CD14, CD11/CD18, toll like receptors, loren protein and LBP and so on ${ }^{[30-32]}$. These receptors also play an important role in LPS-induced inflammatory response. Nucleolin exists on various eukaryotic cell membranes and acts as a receptor for various physiological ligands, which has been confirmed by many studies. After binding to nucleolin, various ligands can be actively transported into the cells, suggesting that nucleolin 
enters the cells through an unclear signal pathway after interacting with LPS to play its biological function. For example, does the direct binding of LPS to cell-surface nucleolin play an important role in the proinflammatory response? What are the downstream signaling molecules and transcription activators of nucleolin-induced inflammatory response? In addition to TNF- $\alpha$, IL- $1 \beta$ and HMGB1, can the blockade of nucleolin can also affect the expression of other inflammatory mediators? Besides the MAPK and NF- $\kappa \mathrm{B}$ signaling pathways, is the inflammatory response mediated by other signaling pathways? In addition, the effects of nucleolin on the mortality, the expression of plasma inflammatory mediators and organ damage in mice need to be further clarified. Solving above-mentioned questions will enrich the LPS-induced proinflammatory mechanisms, providing more valuable insights into the prevention and treatment of Gram-negative bacterial infectioninduced sepsis and other inflammatory diseases.

\section{Open Access}

This article is licensed under a Creative Commons Attribution 4.0 International License https://creativecommons.org/licenses/by/4.0/), which permits use, sharing, adaptation, distribution and reproduction in any medium or format, as long as you give appropriate credit to the original author(s) and the source, provide a link to the Creative Commons licence, and indicate if changes were made. The images or other third party material in this article are included in the article's Creative Commons licence, unless indicated otherwise in a credit line to the material. If material is not included in the article's Creative Commons licence and your intended use is not permitted by statutory regulation or exceeds the permitted use, you will need to obtain permission directly from the copyright holder. To view a copy of this licence, visit http://creativecommons.org/licenses/by/4.0/.

\section{Conflict of Interest Statement}

All authors declare that there is no conflict of interest and financial interest.

\section{REFERENCES}

1 Jia W, Yao Z, Zhao J, et al. New perspectives of physiological and pathological functions of nucleolin (NCL). Life Sci, 2017(10), 186:1-10

2 Mi Y, Thomas SD, Xu X, et al. Apoptosis in leukemia cells is accompanied by alterations in the levels and localization of nucleolin. J Biol Chem, 2003,278(10): $8572-8579$

3 Ugrinova I, Petrova M, Chalabi-Dchar M, et al. Multifaceted Nucleolin Protein and Its Molecular Partners in Oncogenesis. Adv Protein Chem Struct Biol, 2018,111:133-164

4 Storck S, Shukla M, Dimitrov S, et al. Functions of the histone chaperone nucleolin in diseases. Subcell Biochem, 2007,41:125-144

5 Huang $\mathrm{Y}$, Shi $\mathrm{H}$, Zhou $\mathrm{H}$, et al. The angiogenic function of nucleolin is mediated by vascular endothelial growth factor and nonmuscle myosin. Blood, 2006,107(9):3564-
3571

6 Zou J, Wang N, Liu M, et al. Nucleolinmediated pro-angiogenic role of Hydroxysafflor Yellow A in ischaemic cardiac dysfunction: Post-transcriptional regulation of VEGF-A and MMP-9. J Cell Mol Med, 2018,22(5):2692-2705

7 Massimino ML, Simonato M, Spolaore B, et al. Cell surface nucleolin interacts with and internalizes Bothrops asper Lys49 phospholipase A2 and mediates its toxic activity. Sci Rep, 2018,8(1):10619

8 Joo EJ, ten Dam GB, van Kuppevelt TH, et al. Nucleolin: acharan sulfate- binding protein on the surface of cancer cells. Glycobiology, 2005,15(1):1-9

9 Hirano K, Miki Y, Hirai Y, et al. A multifunctional shuttling protein nucleolin is a macrophage receptor for apoptotic cells. J Biol Chem, 2005,280(47):3928439293

10 Seimon TA, Obstfeld A, Moore KJ, et al. Combinatorial pattern recognition receptor signaling alters the balance of life and death in macrophages. Proc Natl Acad Sci USA, 2006,103(52):19794-19799

11 Cohen J. The immunopathogenisis of sepsis. Nature, 2002,420(6917):885-891

12 Diks SH, Richel DJ, Peppelenbosch MP. LPS signal transduction: the picture is becoming more complex. Curr Top Med Chem, 2004,4(11):1115-1126

13 Miki Y, Koyama K, Kurusu H, et al. Nucleolin is a receptor for maleylated-bovine serum albumin on macrophages. Biol Pharm Bull, 2015,38(1):116-121

14 Watanabe $\mathrm{T}$, Tsuge $\mathrm{H}$, Imagawa $\mathrm{T}$, et al. Nucleolin as cell surface receptor for tumor necrosis factor-alpha inducing protein: a carcinogenic factor of Helicobacter pylori. J Cancer Res Clin Oncol, 2010,136(6):911-921

15 Perrone R, Butovskaya E, Lago S, et al. The G-quadruplex-forming aptamer AS1411 potently inhibits HIV-1 attachment to the host cell. Int J Antimicrob Agents, 2016,47(4):311-316

16 Sinclair JF, O'Brien AD. Intimin types $\alpha, \beta$, and $\gamma$ bind to nucleolin with equivalent affinity but lower avidity than to the translocated intimin receptor. J Biol Chem, 2004,279(32):33 751-33 758

17 Kumar S, Gomez EC, Chalabi-Dchar $\mathrm{M}$, et al. Integrated analysis of mRNA and miRNA expression in HeLa cells expressing low levels of Nucleolin. Sci Rep, 2017,7(1):9017

18 Huang XP, Wang X, Xie XL, et al. Cell surfaceexpression ofnucleolinmediates the antiangiogenic and antitumor activities of kallistatin. Oncotarget, 2017,9(2):22202235

19 Su PY, Wang YF, Huang SW, et al. Cell surface nucleolin facilitates enterovirus 71 binding and infection. J Virol, 2015;89(8):4527-4538

20 Fitzgerald KA, Palsson-McDermott EM, Bowie $\mathrm{AG}$, et al. Mal (MyD88-adaper-like) is required for Toll-like receptor-4 signal transduction. Nature, 2001,413(6851):78-83

21 Horng T, Barton GM, Medzhitov R. TIRAP: A adapter molecule in the Toll signaling pathway. Nat Immunol, 2001,2(9):835-841

22 Zhou Y, Zhao Y, Zhao X. et al. Hyperoside Suppresses Lipopolysaccharide-induced Inflammation and Apoptosis in Human Umbilical Vein Endothelial Cells. Curr Med 
Sci, 2018,38(2):222-228

23 Li J, Fan L, Yuan M. et al. Salidroside Inhibits Lipopolysaccharide-ethanol-induced Activation of Proinflammatory Macrophages via Notch Signaling Pathway. Curr Med Sci, 2019,39(4):526-533

24 Luan ZG, Zhang H, Yang PT, et al. HMGB1 activates nuclear factor- $\mathrm{kB}$ signaling by RAGE and increases the production of TNF- $\alpha$ in human umbilical vein endothelial cells. Immunobiology, 2010,215(12):956962

$25 \mathrm{Wu}$ M, Gui H, Feng Z, et al. KPT-330, a potent and selective CRM1 inhibitor, exhibits anti-inflammation effects and protection against sepsis. Biochem Biophys Res Commun, 2018,503(3):1773-1779

26 Fang L, Wang KK, Jiang L, et al. Role of cell-surface nucleolin in lipopolysaccharide-stimulated expression and secretion of TNF-alpha and IL-1 beta. Zhong Nan Da Xue Xue Bao Yi Xue Ban (Chinese), 2008,33(11):9991004

27 Chan CM, Chu H, Zhang AJ, et al. Hemagglutinin of influenza A virus binds specifically to cell surface nucleolin and plays a role in virus internalization.
Virology, 2016,494(7):78-88

28 Chen Z, Xu X. Roles of nucleolin. Focus on cancer and anti-cancer therapy. Saudi Med J, 2016,37(12):13121318

29 Shi H, Huang Y, Zhou H, et al. Nucleolin is a receptor that mediates antiangiogenic and antitumor activity of endostatin. Blood, 2007,110(8):2899-2906

30 Wang S, Deng S, Cao Y, et al. Overexpression of Toll-Like Receptor 4 Contributes to Phagocytosis of Salmonella Enterica Serovar Typhimurium via Phosphoinositide 3-Kinase Signaling in Sheep. Cell Physiol Biochem, 2018,49(2):662-677

31 Zhang $\mathrm{H}$, Zhao C, Li X, et al. Study of monocyte membrane proteome perturbation during lipopolysaccharide-induced tolerance using iTRAQ-based quantitative proteomic approach. Proteomics, 2010,10(15):27802789

32 Ranf S, Gisch N, Schffer M, et al. A lectin S domain receptor kinase mediates lipopolysaccharide sensing in Arabidopsis thali-ana. Nat Immuno1, 2015,16(4):426433

(Received June 19, 2019; accepted May 5, 2020) 